\title{
Tuberculosis of the Spine (L5, S1) Secondary to Scrofuloderma with Viral Warts in a 15-Year-Old Male
}

\author{
Akunnaya Chioma Ohanenye, Nneka Chioma Okoronkwo \\ Department of Paediatrics, Abia State University Teaching Hospital, Aba, Nigeria \\ Email: chiobeta@yahoo.com,nnekaceo@rocketmail.com
}

How to cite this paper: Ohanenye, A.C. and Okoronkwo, N.C. (2018) Tuberculosis of the Spine (L5, S1) Secondary to Scrofuloderma with Viral Warts in a 15 -Year-Old Male. Case Reports in Clinical Medicine, 7, 70-83.

https://doi.org/10.4236/crcm.2018.71007

Received: December 12, 2017

Accepted: January 16, 2018

Published: January 19, 2018

Copyright (c) 2018 by authors and Scientific Research Publishing Inc. This work is licensed under the Creative Commons Attribution International License (CC BY 4.0). http://creativecommons.org/licenses/by/4.0/

\begin{abstract}
We report this case of a 15-year-old male who presented to the children outpatient clinic (CHOP) of Abia State University Teaching Hospital (ABSUTH), Aba on the $5^{\text {th }}$ of November 2015. He had tuberculosis (TB) of the skin (scrofuloderma) which was not diagnosed and had received treatment other than anti-TB medication. He now presented 9 years after with multiple body discharging sinuses, cicatricial skin lesions, tuberculosis of the spine (L5, S1) with contracture of the Achilles Tendon and genital warts. Subsequent treatment with full anti-TB drugs led to resolution of his illness. A higher index of suspicion is required for early diagnosis of extrapulmonary TB. Prompt and adequate treatment with anti-TB medication ensures cure in such cases. Appropriate control program is also known to improve the outcome and reduce sequelae.
\end{abstract}

\section{Keywords}

Tuberculosis, Spine, Scrofuloderma, Viral Warts, Anti-TB Drugs, ABSUTH

\section{Introduction}

Extra Pulmonary Tuberculosis (EPTB) is seen in patients with tuberculosis of organs other than the lungs e.g. pleura, lymph nodes, abdomen, genitourinary tracts, skin, joint, bone and meninges.

Solagberu and Ayorinde [1] documented that data on tuberculosis of the spine from Nigeria is scanty despite the endemicity of the disease.

In 2013, Kanojia et al. [2] reported Pott's paraplegia $2^{\circ}$ to scrofuloderma for the first time in a 29 -year-old female.

A TB case is one who is bacteriologically confirmed or clinically diagnosed by 
a clinician to have tuberculosis [3].

In a study by Awi and Nte in Port Harcourt, Nigeria, TB spine was found to be $3.8 \%$, while pulmonary TB was $80.6 \%$ of all forms of TB [4].

Of the 2610 cases of childhood TB in a study from Abidjan, 77.24\% were pulmonary while $22.76 \%$ were extrapulmonary [5].

An estimated 1.3 million cases of tuberculosis and 450,000 associated deaths occur annually in children, with EPTB accounting for up to one third of all cases [6].

Extrapulmonary TB is seen more in children than adults [6].

$\mathrm{TB}$ of the spine may arise from lymphatic spread from adjacent areas e.g. pleura or from any of the following [7]:

- Haematogenous spread from primary foci.

- Lesions may originate in the body of one or more vertebrae and spread to adjacent tissues sparing spinous processes and posterior arches.

Mid and lower thoracic vertebrae are the commonest areas affected followed by lumbar and cervical vertebrae. TB spine may show features of spinal cord compression by collapsed vertebrae or paraspinal abscess. The later may cause increase in muscle tone, brisk deep tendon reflexes and clonus. There could be paraplegia and loss of bladder control. Caseous pus may also track along muscles causing psoas abscess especially, with T12 or lumbar vertebrae involvement [7].

Cold abscesses may be seen on X-Ray [7].

We hereby present a case of a 15-year-old boy who was not detected to have had pulmonary tuberculosis, nor received anti-TB treatment, until he came to us after 9 years of sinus discharge of pus from different areas of his body.

To the best of our knowledge, this is the first case of extrapulmonary TB showing association between scrofuloderma and TB of the lower spine with a viral infection of the penile shaft/scrotal sac in a teenager at ABSUTH, and in Abia State of Nigeria.

\section{Case Report}

The index patient, a 15-year-old male first presented at ABSUTH on the $5^{\text {th }}$ of November 2015, with a 9 years history of multiple wounds, discharging pus, which was first noticed on the Armpit, then on the legs and thighs. He said the lesions were healing with scar tissues which became multiple with time. The ones on the lower limbs progressively involved the pelvic region, abdomen and the back.

Scrotal swelling, excoriations and discharge from penis and inguinal region started three weeks (3/52) prior to presentation.

Wounds were in different stages of healing. Evidence of weight loss was prominent and been progressive since onset of sickness. There was history of chronic cough which was said to be mild. He had an episode of hemoptysis at the early years of the illness, but no fever, nor night sweats. No history of contact with an adult with chronic cough. No similar illness in other members of his family. 
He had difficulty coping with school activities. There was history of poor quality of life with friends and peers, and poor personal body image. During this active phase of the illness, he was taken by his parents to several private hospitals looking for cure, with no relief.

Past treatment history: He had been admitted in various private hospitals in Aba, in the past, for complaints of same illness. He usually had drainage of his abscesses and antibiotics coverage, after which they will discharge him.

He received this treatment at every interval of one to two weeks, with no relief of symptoms. Ibuprofen was also given regularly to relieve inflammation and pains. In the course of his treatment over the years, he received two pints of blood transfusions.

- His pregnancy and birth history was uneventful.

- His development was normal for age.

- He was in the $3^{\text {rd }}$ grade of his Junior Secondary School, and was performing as an average student.

- Immunization history showed that he did not receive BCG at birth.

Family/Social History: He is the $6^{\text {th }}$ child, out of 8 children, in a monogamous setting. The $5^{\text {th }}$ child died at the age of 6yrs from a febrile illness. Other siblings are alive and well. Father is a 52 year old tricycle driver with primary education while mother is a 44 year old housewife with secondary education.

They all live in a two room apartment with two small windows in each room. Sleeping arrangement is overcrowded, with about $6-8$ people sleeping in a room. They share public toilet with other members of the yard, and drink unboiled water from the borehole.

Examination revealed an underweight teenager, weighing $35 \mathrm{~kg}$. He was afebrile $\left(\mathrm{T}=36.2^{\circ} \mathrm{C}\right)$ with no obvious peripheral lymphadenopathy. He had moderate palor, no jaundice and no digital clubbing. There were multiple puckered scars and ulcers at different stages of healing (Figure 1 \& Figure 2) all over his

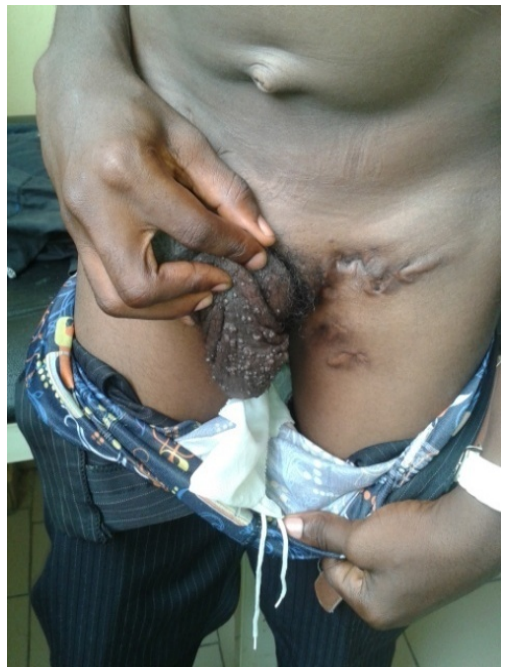

Figure 1. Genital Warts Reproduced with permission. 


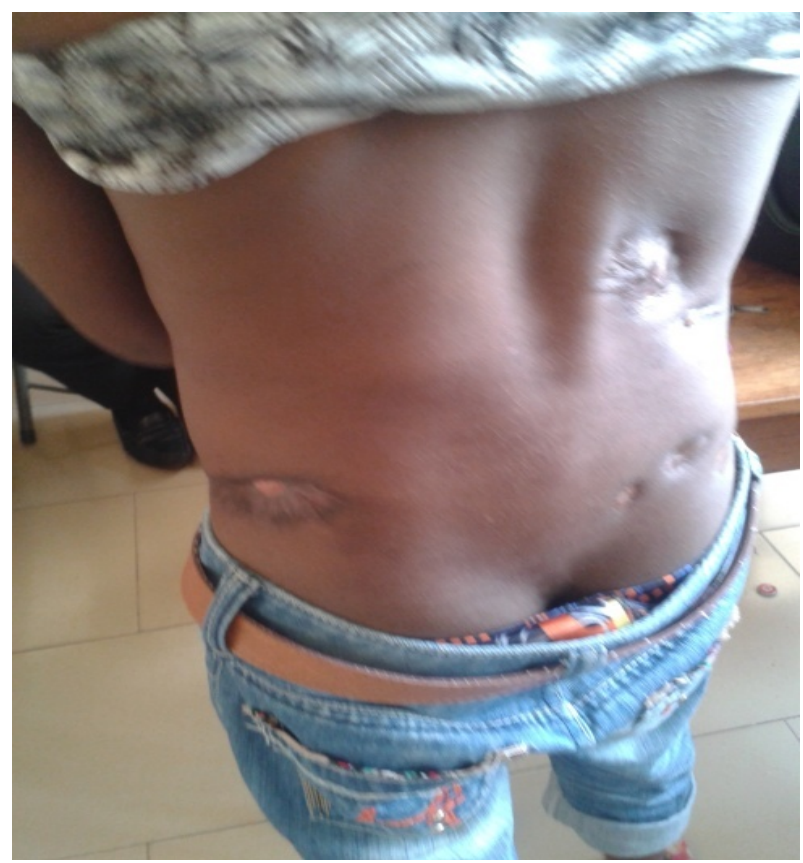

Figure 2. Sinus Discharge from scrofuloderma Reproduced with permission.

body. Mostly involved were the lower back and groin regions. Some sinuses were discharging pus at the armpit, the thorax, abdomen, inguinal regions, both thighs, penile shaft, scrotal sacs, and chest region. The ankle wound already had severe contracture at the Achilles tendon pulling the heel upwards, and this prevented flat walking causing him to tip-toe on his foot (Figure 3)

He was not in respiratory distress and chest was clinically clear. The digestive system was normal but for prominent geographical tongue (Figure 4). Inguino-scrotal area showed multiple puckered scars, with florid viral lesions over the penile shaft and scrotum (Figure 1). The scrotum was very firm to touch with discharging sinuses.

Central Nervous System, was normal except for an abnormal gait which was due to the contracture of the Achilles tendon secondary to the scar tissues.

Cardiovascular system showed a normal heart rate (90 beats/min), and a Blood Pressure of 100/70 mmHg. There were normal heart sounds and no murmur.

A diagnosis of Actinomycosis infection to rule out Extra-pulmonary TB was made.

The father refused admission for investigations due to financial constraints. He came back five days later $\left(10^{\text {th }}\right.$ November 2015) for the investigations.

The following investigations were eventually carried out:

Complete Blood Count (CBC) - PCV of 0.34\% (30.2\% - 47.5\%)

Erythrocyte Sedimentation Rate (ESR) $-73 \mathrm{~mm} / \mathrm{hr}$.

White Blood Cell (Total) $-10.5 \times 10^{3}\left(2.6-10.3 \times 10^{3}\right)$

Differentials-Neutrophil 80\% (38.3\% - 77.1\%) 


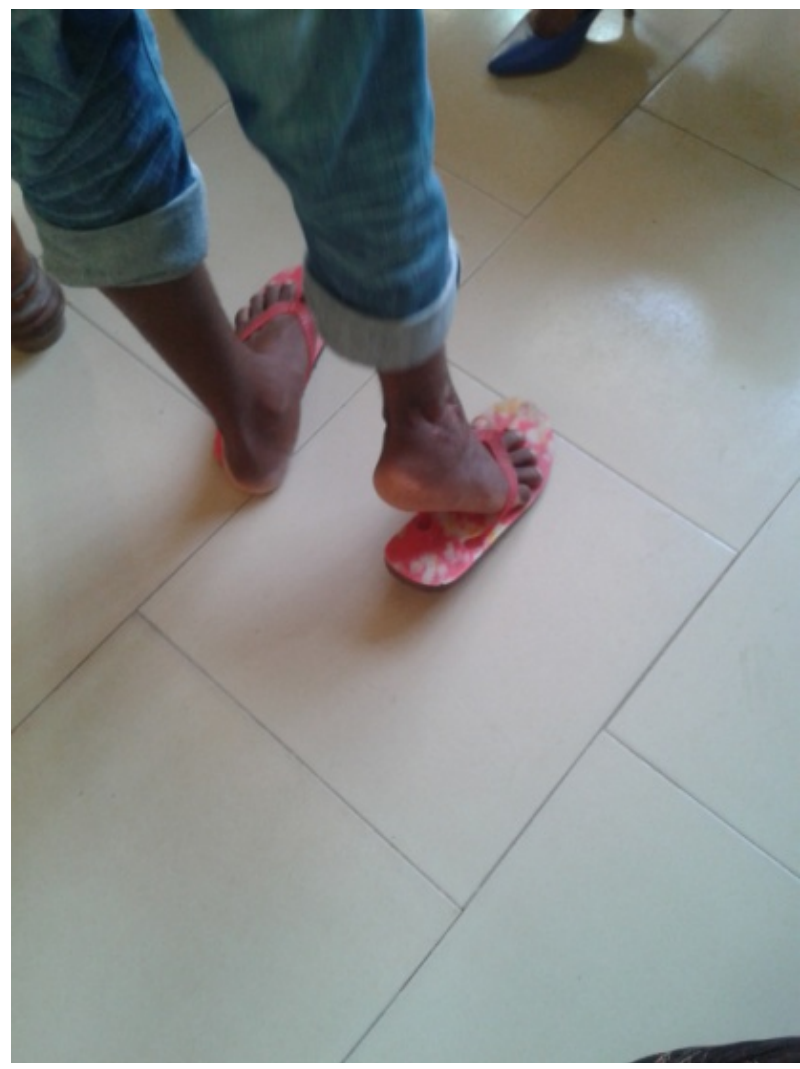

Figure 3. Contracture of Achilles Tendon Reproduced with permission.

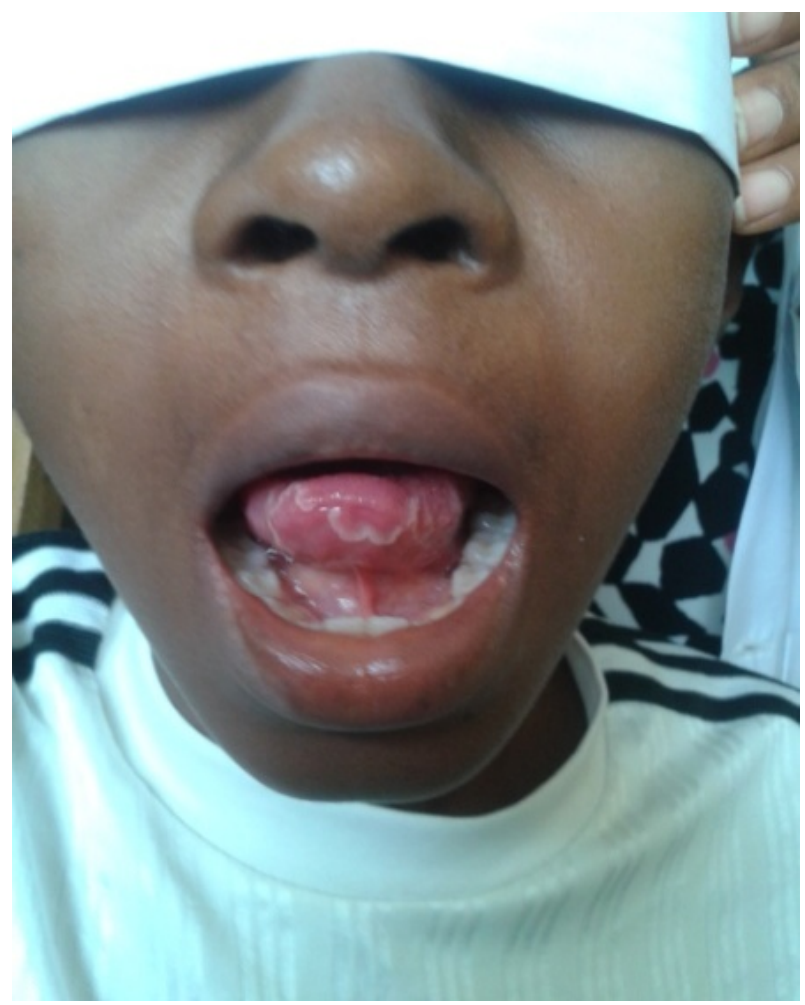

Figure 4. Oral Lesions Reproduced with permission. 
- Lymphocyte 18\% (15\% - 47.9\%)

- Eosinophil 00\%

- Monocyte $2 \%$

- Basophil 00\%

MantouxTest-Positive after $48 \mathrm{hrs}$ reading $13 \mathrm{~mm}$

- Chest X-Ray (CXR) - mild hilar lymphadenopathy (Figure 5)

- X-Ray of the lumbosacral spine showed degeneration and collapse of the vertebrae and loss of joint spaces, involving L5, S1 and upper sacral spine, Spondylolisthesis of S1 and L5 was evident. (Figure 6 \& Figure 7)

- Wound swab for Ziehl Nelson staining was negative

- Wound culture-yielded moderate growth of Escherichia coli

- Fine needle aspirate and cytology-were not done

- VDRL test was non-reactive-Negative

- Human Immunodeficiency Virus (HIV) Screen-Negative

- Sulphur granules assay for actinomyces-negative

- Sputum for Xpert MTB/RIF-was negative for mycobacterium tuberculosis, sensitive to first line anti TB drugs

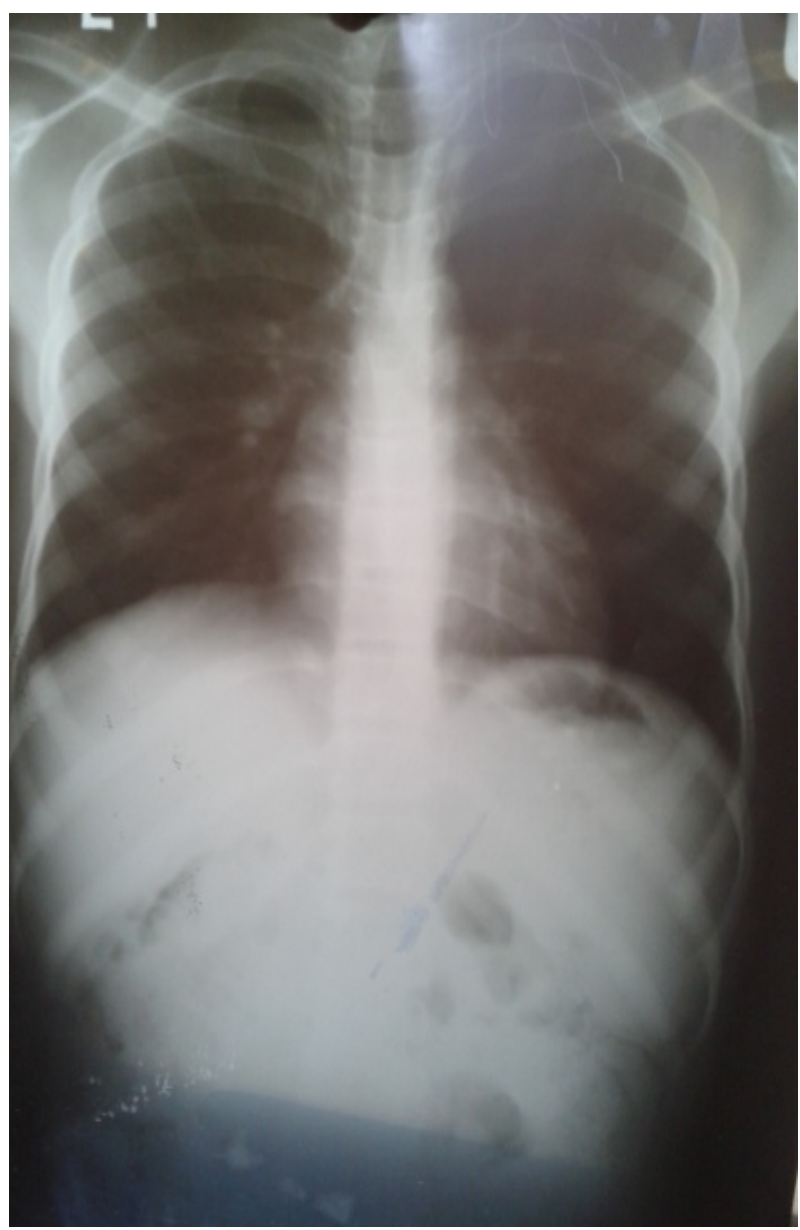

Figure 5. Chest X-Ray with mild hilar lymphadenopathy Reproduced with permission. 


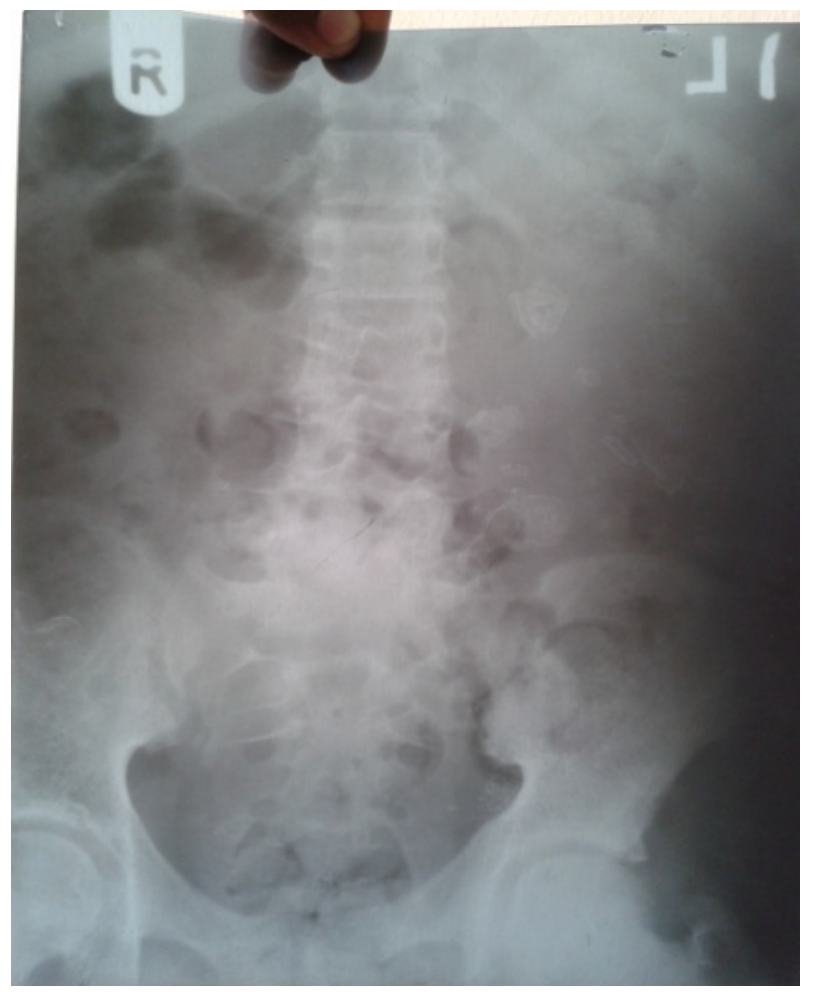

Figure 6. Degeneration collapse of vertebrae and loss of joint spaces L5, S1 Reproduced with permission.

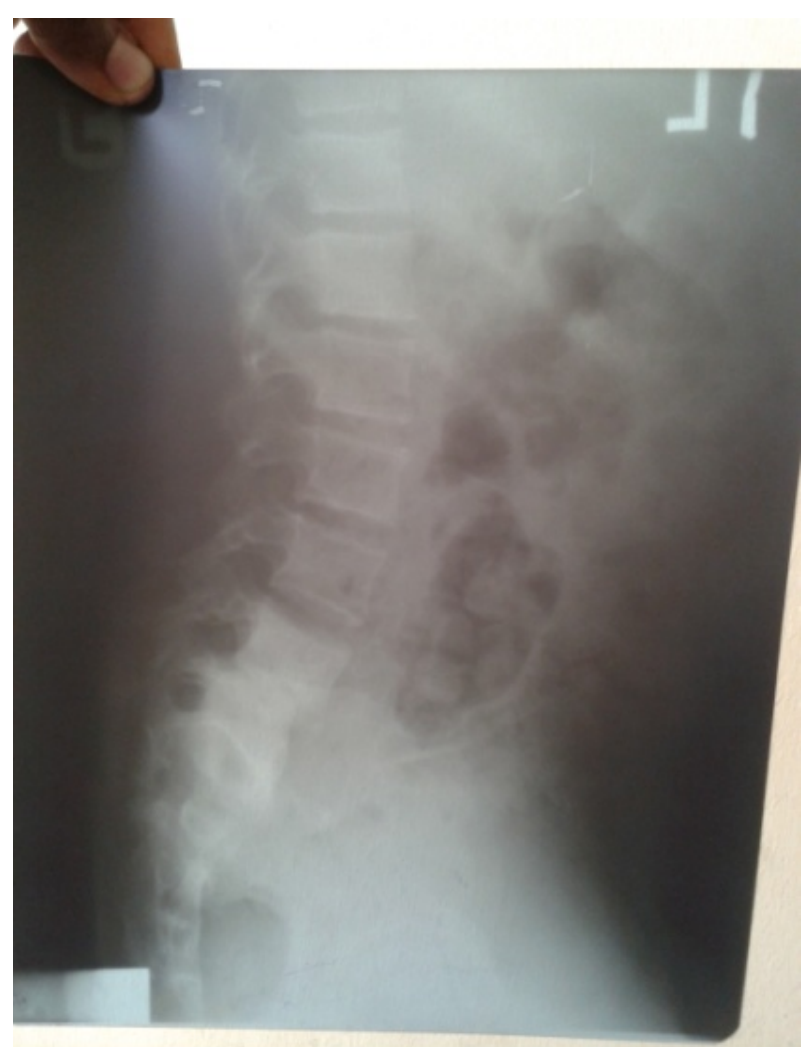

Figure 7. Lateral view of L5, S1 Compression Reproduced with permission. 
- Smear for AFB-was negative

- Blood culture ordered-was not done due to financial constraints

Initially he was commenced on 7 days of intravenous crystalline penicillin G, when actinomycosis was suspected, and while waiting for test results to confirm tuberculosis. Thereafter, antibiotics was changed to Amoxicillin/Clavulanate tablet, $625 \mathrm{mg} 12$ hourly for another one week. He was also on haematinics and nutritional rehabilitation which continued even after the antibiotics. Two weeks into patient management, a weight gain of $2 \mathrm{~kg}$ was recorded (new weight $=37$ $\mathrm{kg})$.

All the laboratory and X-RAY results were finally available towards the completion of the antibiotics. The patient felt a bit better clinically but the sinuses were still discharging and sore.

Based on the history, positive mantoux test, Vertebral X-RAY and CXR results, a diagnosis of extra pulmonary TB (Scrofuloderma and Potts disease of the spine) was entertained. The viral warts were believed to be secondary to immunosuppression from TB. Decision was to commence full anti-Koch's therapy immediately using Isoniazid (INH), Rifampicin, Pyrazinamide, Ethambutol according to NTBLCP guideline.

The father and child were properly counseled on TB treatment. Due to logistics and delay on the side of the parents, anti-TB drugs were finally started on $8 / 12 / 2015$.

Surgical consult was sent to plastic surgical unit for Achilles tendon review and possible release, but due to financial constraints, there was no follow up on that aspect of management.

He was on the initiation phase of treatment with 4 drugs (INH, Rifampicin, Pyrazinamide, and Ethambutol). Other adjuvants like pyridoxine were added.

After the initiation phase of 2 months on anti-Kochs drugs, he continued with only INH and Rifampicin for another 16 months. Compliance was optimal. Just after one month on anti TB drugs, he gained $5 \mathrm{~kg}$ body weight (weight then became $40 \mathrm{~kg}$ ).

A repeat of $\mathrm{CBC}$ same time showed some haematological improvement:

WBC 6.8, Hb 10.4, HCT $31.2 \%$, platelets $337 \times 10^{3} /$ ul, lymphocyte $29 \%$, Neutrophil $57.6 \%$.

ESR became $34 \mathrm{~mm} / \mathrm{hr}$ after 2 months, and $15 \mathrm{~mm} / \mathrm{hr}$ after 6 months of antiTB treatment. Normal range for ESR is $<15 \mathrm{~mm} / \mathrm{hr}$.

The multiple discharges from sinuses and areas of ulceration were healing, although scar tissues were still prominent (Figure 8 \& Figure 9).

Follow up was adequate, making sure adherence to anti-Koch's therapy was maintained. He remained afebrile throughout the course of treatment with a temperature ranging from $36^{\circ} \mathrm{C}-37.2^{\circ} \mathrm{C}$.

On his last appointment 4 months ago, before our hospital went on an industrial action (because of non-payment of salaries), he was on his last month of anti-TB treatment. He had been gaining weight progressively. Multiple body ulcers 


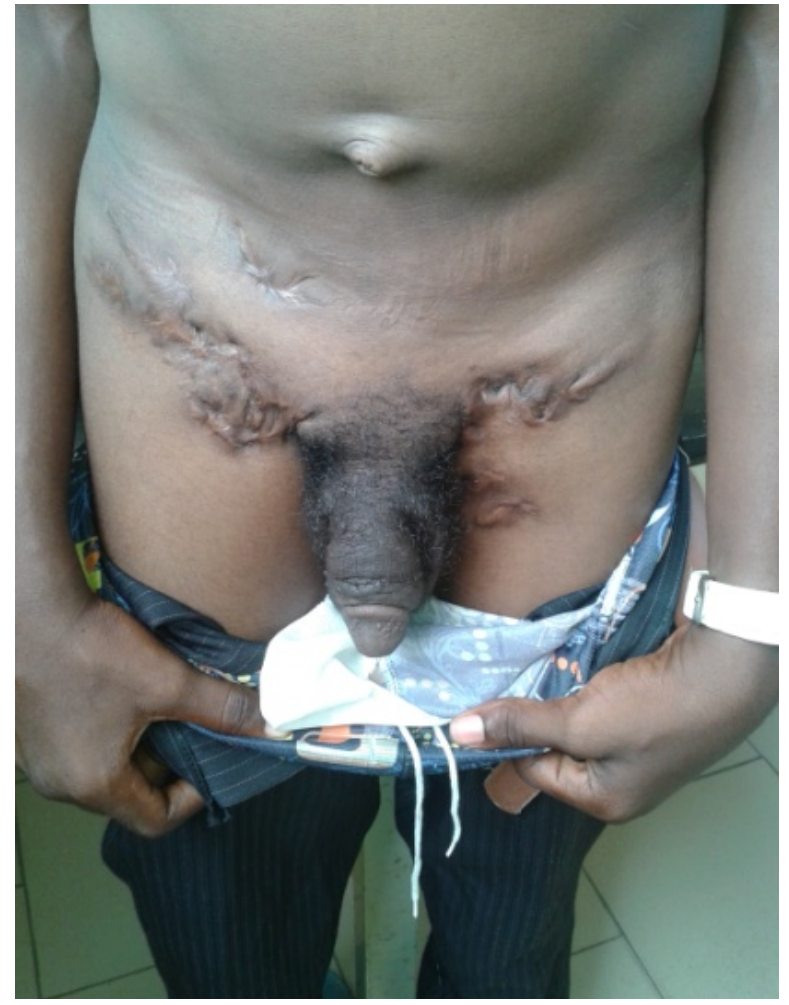

Figure 8. Healing Viral Warts Reproduced with permission.

and sinuses were all healed and closed up. Cicatricial tissues were however still present measuring about $5-7 \mathrm{~cm}$ on affected areas (Figure 8 \& Figure 9). Also noticed were clearing of viral warts which responded well to the antiviral drug, Acyclovir (both tablet and cream). The penis was now of normal size and shape (Figure 8).

Patient and parents were happy, his social life had improved, and he was no longer absent from schools. He also testified to a better self-image.

\section{Discussion}

It is estimated that 1.3 million cases of tuberculosis and 450,000 associated deaths occur annually in children, with EPTB accounting for up to one third of all cases [6].

EPTB has been on the increase worldwide [8] [9]. This therefore calls for a higher index of suspicion in making early diagnosis, which eventually improves outcome. The index patient in this study has been receiving treatment over several years for wrong diagnoses other than TB. Inadequate knowledge and skill in identifying presumptive TB cases in children, and its management remains a global problem. Prompt diagnosis and treatment of his EPTB would have saved him all the years of clinical agony and wasted resources.

Overcrowding, younger age, poor socioeconomic status and absence of BCG immunization are risk factors for the development of TB generally [9]. All these risks factors were prominent in our index case. He noticed the sinuses initially 9 


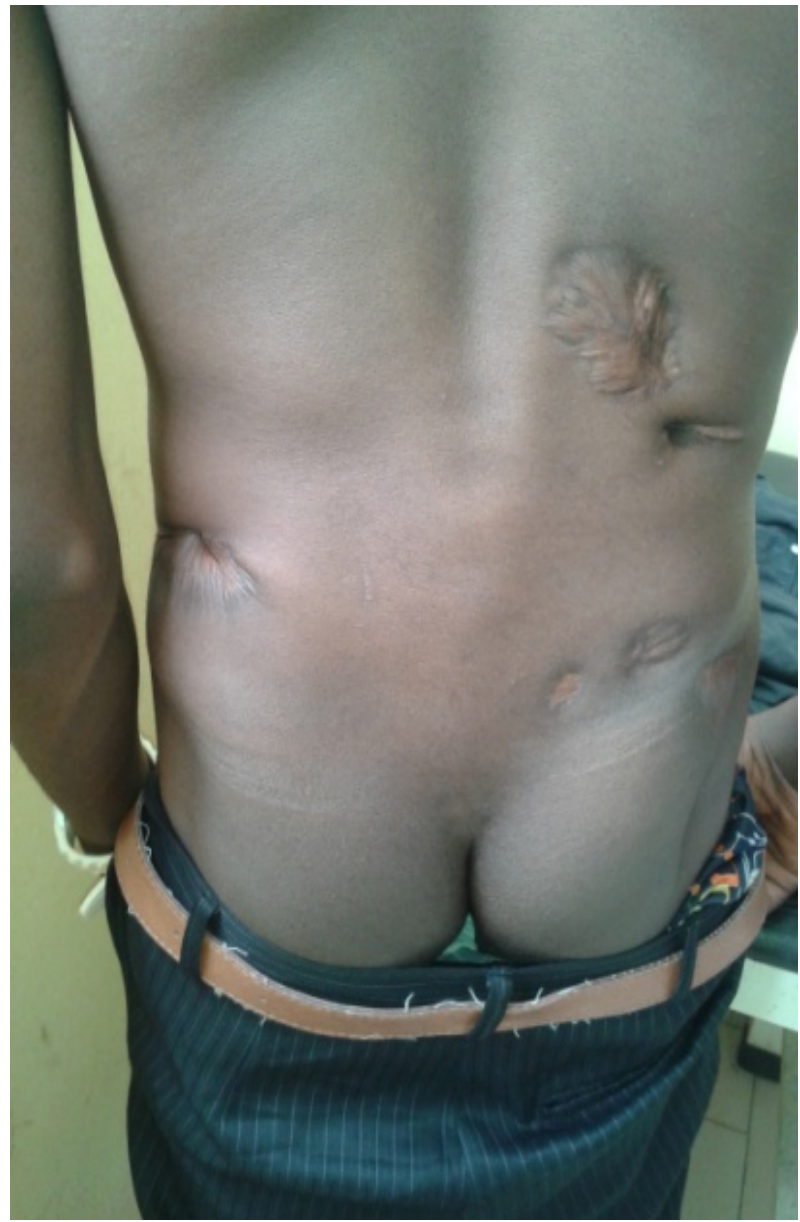

Figure 9. Healing with Cicatricial wound Reproduced with permission.

years prior to presentation when he was only 6 years of age. Their whole family lives in a two bedroom apartment. The parents' economic status was obviously low with financial constraints that affected the smoothness of his medical management. Again, he was not given any BCG immunization at infancy.

The history of chronic cough, haemoptysis and cold abscesses (forming sinuses) in our patient warranted the need to rule out actinomyces infection. This diagnosis was discarded when sulfur granule test and gram stain of the purulent discharges from the sinuses came back negative for actinomyces bacteria infection. It is a documented fact that Actinomyces infection can be a differential diagnoses for pulmonary and extrapulmonary TB in children [10].

Making the diagnosis of TB in our index patient was not easy because we did not isolate mycobacterium tuberculosis and Ziehl Nielsen test was negative. However, the chronicity of his cough, a history of haemoptysis, weight loss, and positive mantoux test increased our suspicion of TB. Although the hilar lymphadenopathy on his CXR was not very prominent, the CXR film did not appear typically normal. Again, the viral warts were a sign of immunosuppression despite the fact that he was HIV negative. All these increased our suspicion for 
EPTB.

Although the diagnosis of extrapulmonary TB has always been a problem for clinicians [11], World Health Organization states that the diagnosis of EPTB should be made on the basis of a culture-positive specimen or caseating granuloma on biopsy or strong clinical evidence consistent with active EPTB [12]. Our patient had strong clinical evidence suggestive of active EPTB.

The extrapulmonary sites of TB involvement in our patient were the spine and the skin. The association between scrofuloderma and TB of the spine is well documented in literature [1] [2] [13].

The genital viral warts seen on our patient may be explained by immunosuppression secondary to TB. It may also be a Tuberculosis verrucosa cutis [14] since no viral test was done to confirm the viral aetiology of the warty lesion. The later is cured by anti-TB drugs while viral warts are treated using antiviral medications like acyclovir. The patient received both acyclovir and Anti TB drugs. The genital lesions disappeared while he was on treatment.

The use of INH, Rifampicin, Pyrazinamide, and Ethambutol for the first 2 months and continuation with only INH and Rifampicin for another 4 to 16 months has been the mainstay of treatment for EPTB [15] [16].

We used the 18 months treatment protocol in view of the fact that the spine was also involved, and would require a longer duration of treatment for complete cure.

When EPTB is properly diagnosed and adequate treatment is given, cure is rapid and complications (if any) are minimal. This is because adequate early pharmacological treatment can prevent severe complications [16].

Our patient had optimal follow up from time of diagnosis until he completed his treatment. Although financial constraint made the surgical aspect of his treatment not possible presently, he has shown profound signs of clinical recovery. Follow up is a very important aspect of the management of EPTB. For such patients, bacteriological evaluation of the response to treatment is often limited by the difficulty in obtaining follow-up specimens [17]. Response often must be judged on the basis of clinical and radiographic findings [16]. Our patient could not afford extra radiological investigations, after the initial ones, due to financial constraints.

There has been marked improvement evidenced by increasing weight gain, healing of all the ulcers and sinuses, clearing of viral warts, increased feeling of well-being and improved self-esteem. He has resumed his academic career, while hoping for funds to release his contractures.

\section{Conclusion}

Extrapulmonary TB is still a public health problem among children. A higher index of suspicion is required to make this diagnosis. Prompt and adequate treatment with anti TB drugs ensures rapid cure and prevents/minimizes complications. 


\section{Recommendation}

- We recommend that diligent contact tracing of TB cases through screening of school children and house to house screening be encouraged.

- The government should create more awareness to the public on both pulmonary and extrapulmonary TB cases.

- More doctors and other health workers should be trained specifically on how to recognize both typical and atypical cases of TB.

- Doctors in private practice should be encouraged to do early referral of difficult cases to tertiary health institutions where other health experts can help in the management of such cases.

- Bold government policies with good commitment to TB control and prevention will help to fight this pandemic. Treatment (medical and surgical) of every form of childhood TB should be made free by the government. There is also the need to improve the economic status and living environment of the masses. The national program on immunization should ensure more coverage to avoid missed immunizations.

\section{Consent}

A written informed consent was obtained from the patient's father for this publication and the pictures. A copy of it is available for review by the editor-in chief of this journal.

\section{Author's Contribution}

Both Dr Ohanenye and Dr Okoronkwo designed, wrote and edited the manuscript.

\section{Conflict of Interest}

There is no conflict of interest.

\section{Funding}

None.

\section{References}

[1] Grillo, G., Solagberu, B.A. and Ayorinde, R.O. (2001) Tuberculosis of the Spine in Iloron Nigeria. East African Medical Journal, 78, 197-199.

[2] Kanojia, R.K., Kalra, M., Sareen, A. and Reddy, K.B. (2013) Pott's Paraplegia $2^{\circ}$ to Scrofuloderma Is a Rare Association. Spinal Cord, 51, 931-933.

[3] World Health Organization. (2014) Guidance for National Tuberculosis Programme on the Management of Tuberculosis in Children. 2nd Edition, WHO Library Cataloguing-in-Publication, 21-22.

[4] Awi, D.D. and Nte, A. (2007) Upsurge of Paediatric Tuberculosis in Port Harcourt, Nigeria: Has HIV Infection Any Role? Port Harcourt Medical Journal, 1, 113-118. https://doi.org/10.4314/phmedj.v1i2.38866 
[5] Cardenat, M., Horo, K., Amon Tanoh Dick, F., Lasme-Guillao, E., N'Guessan, R. and Ahui, J.M. (2014) Tubeculosis in Abidjan: Comparison of Children and Adults. Medecine et Sante Tropicales, 24, 289-293. https://doi.org/10.1684/mst.2014.0362

[6] Maltezou, H.C., Spyridis, P. and Kafetzis, D.A. (2000) Extra-Pulmonary Tuberculosis in Children. Archives of Disease in Childhood, 83, 342-346.

https://doi.org/10.1136/adc.83.4.342

[7] Cruz, A.T. and Starke, J.R. (2007) Clinical Manifestations of Tuberculosis in Children. Paediatric Respiratory Reviews, 8, 107. https://doi.org/10.1016/j.prrv.2007.04.008

[8] Peto, H.M., Pratt, R.H., Harrington, T.A., Lo Bue, P.A. and Armstrong, L.R. (2009) Tuberculosis in the United States, 1993-2006. Clinical Infectious Diseases, 49, $1350-1357$.

[9] García-Rodríguez, J.F., Álvarez-Díaz, H., Lorenzo-García, M.V., Mariño-Callejo, A., Fernández-Rial, Á. and Sesma-Sánchez, P. (2011) Extrapulmonary Tuberculosis: Epidemiology and Risk Factors. Enfermedades infecciosas y microbiologia clinica, 29, 502-509.

[10] Sénéchal, A., Dupieux, C., Karsenty, J., Lustig, S., Breton, P., et al. (2014) Actinomycosis: Etiology, Clinical Features, Diagnosis, Treatment, and Management. Infection and Drug Resistance, 7, 183-197.

[11] Purohit, M.R., Sviland, L., Wiker, H. and Mustafa, T. (2017) Rapid and Specific Diagnosis of Extrapulmonary Tuberculosis by Immunostaining of Tissues and Aspirates with Anti-MPT64. Applied Immunohistochemistry \& Molecular Morphology, 25, 282-288. https://doi.org/10.1097/PAI.0000000000000300

[12] World Health Organization. (2013) Global Tuberculosis Control: WHO Report. http://www.who.int/tb/publications/global_report/en/index.html

[13] Ekenna, O. (2016) Skin and Soft Tissue Infections in: Cases in Clinical Infectious Disease Practice. John Wiley and Sons, Inc., Hoboken, New Jersey, p. 11.

[14] Rajan, J., Mathai, A.T., Prasad, P.V.S. and Kaviarasan, P.K. (2011) Multifocal Tuberculosis Verrucosa Cutis. Indian Journal of Dermatology, 56, 332-334. https://doi.org/10.4103/0019-5154.82500

[15] Jain, A.K. (2010) Tuberculosis of the Spine: A Fresh Look at an Old Disease. The Journal of Bone and Joint Surgery, 92, 905-913. https://doi.org/10.1302/0301-620X.92B7.24668

[16] Rasouli, M.R., Mirkoohi, M., Vaccaro, A.R., Yarandi, K.K. and Movaghar, V.R. (2012) Spinal Tuberculosis: Diagnosis and Management. Asian Spine Journal, 6, 294-308. https://doi.org/10.4184/asj.2012.6.4.294

[17] Lee, J.Y. (2015) Diagnosis and Treatment of Extrapulmonary Tuberculosis. Tuberculosis and Respiratory Diseases (Seoul), 78, 47-55.

https://doi.org/10.4046/trd.2015.78.2.47 


\section{Abbreviations}

MTB: Mycobacterium Tuberculosis

XPERT MTB/RIF TEST: Gene Expert Mycobacterium

Tuberculosis/Rifampicin Sensitivity Test

DS-TB: Drug Susceptibility Tuberculosis

HCT: Haematocrit 